Article

\title{
Hip Flexibility and Dynamic Balance Ability in Soccer Players with Functional Ankle Instability
}

\author{
Akihiro Tamura ${ }^{1, *}$, Keita Shimura ${ }^{2}$ and Yuri Inoue ${ }^{3}$ \\ 1 Department of Physical Therapy, School of Health Sciences at Narita, International University of Health and \\ Welfare, Narita 286-8686, Chiba, Japan \\ 2 School of Health Sciences, Tokyo International University, Kawagoe 350-1197, Saitama, Japan; \\ kshimura@tiu.ac.jp \\ 3 Department of Rehabilitation, Maruyama Orthopaedic and Rehabilitation Clinic, \\ Takarazuka 665-0021, Hyogo, Japan; chiroyuri@gmail.com \\ * Correspondence: akihiro.tamura@iuhw.ac.jp; Tel.: +81-476-20-7717
}

check for updates

Citation: Tamura, A.; Shimura, K.; Inoue, Y. Hip Flexibility and Dynamic Balance Ability in Soccer Players with Functional Ankle Instability. Trauma Care 2021, 1, 206-214. https:/ /doi. org/10.3390/traumacare1030018

Received: 30 September 2021 Accepted: 1 December 2021 Published: 3 December 2021

Publisher's Note: MDPI stays neutral with regard to jurisdictional claims in published maps and institutional affiliations.

Copyright: (c) 2021 by the authors. Licensee MDPI, Basel, Switzerland. This article is an open access article distributed under the terms and conditions of the Creative Commons Attribution (CC BY) license (https:/ / creativecommons.org/licenses/by/ $4.0 /)$.

\begin{abstract}
The prevention of recurrent ankle sprain and functional ankle instability in soccer players is essential. This study clarified hip joint mobility and dynamic balance ability in soccer players with functional ankle instability. This case-control study included 17 male college soccer players. All participants were assessed using the Cumberland Ankle Instability Tool and were divided into chronic ankle instability (CAI) and non-CAI groups for each of their dominant and nondominant legs. Bilateral passive hip range of motion (ROM) was assessed and the modified Star Excursion Balance Test (mSEBT) was measured for each leg. In the dominant leg, the reach in the posterolateral direction in the CAI group was significantly less than that in the non-CAI group. Hip internal rotation angles in the dominant leg in the CAI group were greater than those in the non-CAI group; however, no significant correlations with the three directions of mSEBT were observed. In the nondominant leg, mSEBT and hip ROMs did not show any significant differences between groups. The dominant leg in soccer players with CAI had poor dynamic balance ability while reaching posterolaterally. However, acquiring hip flexibility may not be necessary to improve the dynamic balance ability. These findings may help develop future research.
\end{abstract}

Keywords: ankle sprain; range of motion; balance

\section{Introduction}

Ankle sprains have often been reported as the most common ankle injuries in soccer and football [1-3], and accounted for up to $67 \%$ of all soccer-related ankle injuries [4]. After the first ankle sprain, 73\% of patients have a high rate of recurrence [5,6], most often in noncontact situations [3,7]. An English Premier League survey reported that anterior talofibular ligament injury associated with ankle varus sprain represented $31.1 \%$ of all ankle disorders, with an average of 43.4 days between injury and returning to play [7]. Ankle sprain in soccer and football is a major factor preventing return to play. It is important to prevent the first ankle sprain and its recurrence.

Instability of the ankle joint tends to remain following the structural and functional failure of the sprain [8-10]. This pathological condition is broadly named "chronic ankle instability" (CAI) [11]. It can occur either or both as functional ankle instability (FAI) and mechanical (structural) ankle instability (MAI) [11,12]. An epidemiological survey by Hiller et al. (2011) reported that $81 / 175$ cases had CAI after an ankle sprain [8]. This pathology is caused by specific insufficiencies in proprioception, neuromuscular control, postural control, strength, and factors that alter the mechanics of one or more joints within the ankle complex [13]. Moreover, there is evidence that instability in the ankle joint alters postural control ability, which is associated with increased risk of sustaining acute ankle sprain $[13,14]$. Furthermore, ankle instability and recurrent sprains may damage the 
articular surface of the joint and increase the risk of developing osteoarthritis [15]. Thus, ankle sprain has a high risk for resulting in CAI, which might underlie the increased risk of reinjuring the sprain, with possible secondary injury.

The hip joint plays an important function in maintaining upright posture and balance. Recent studies $[16,17]$ have suggested that individuals with CAI have weaker knee and hip muscles than those without CAI or those who have no ongoing problems. Hip strength in individuals with CAI has been shown to be related to posterolateral balance performance [16]. These reports indicated that hip strength is important for maintaining dynamic balance in individuals with CAI. Hip joint flexibility has also been associated with dynamic balance performance [18-20]. Endo et al. (2014) showed that dynamic balance ability for the medial direction was significantly positively correlated with hip internal rotator tightness and hamstring tightness [20]. In addition, some of these previous studies have evaluated dynamic balance ability using the Star Excursion Balance Test (SEBT) $[19,20]$. The SEBT has been widely used to measure dynamic balance ability in the lower extremity, and is a reliable test that can simultaneously assess the range of motion (ROM), flexibility, neuromuscular control and strength [21,22]. Therefore, these studies suggest that hip flexibility in soccer players with CAI might affect their dynamic balance ability, and that acquiring hip flexibility could help them to improve their dynamic balance ability, as evaluated by the SEBT.

To our knowledge, no previous study has focused on whether soccer players with CAl have poor hip joint flexibility after ankle sprain. Furthermore, it is unclear whether hip function in soccer players with CAI is associated with dynamic balance ability evaluated by the SEBT. Therefore, the purpose of this study was to clarify hip joint mobility and dynamic balance ability in soccer players with CAI. The findings of this study can provide a basis for investigations into preventing the recurrence of CAI and related secondary disorders in soccer and football players.

\section{Materials and Methods}

\subsection{Study Design and Participants}

This was a case-control study. All trials were conducted in the motion analysis laboratory of International University of Health and Welfare Narita Campus in Japan. In total, 17 male college soccer players (mean age, $20.8 \pm 0.3$ years; mean height, $173.0 \pm 5.1 \mathrm{~cm}$; and mean weight, $65.8 \pm 3.9 \mathrm{~kg}$ ), recruited from August 2019 to January 2020, were included in this study. All participants had soccer playing experience of more than 8 years (mean playing experience, $10.5 \pm 2.1$ years). All were right-footed in the dominant leg (kicking leg) and left-footed in the nondominant leg (supporting leg). The players' positions in soccer were: strikers, seven; midfielders, four; and defenders, six. The participants confirmed their intention to participate. They were required to answer a questionnaire related to their physical characteristics, current medical information, and medical history.

The inclusion criteria were: age, $>18$ years; playing soccer experience, $>8$ years; and absence of current pain in the lower extremities during their daily activities. The exclusion criteria included any orthopedic history of the trunk, hip, or knee, and any ankle surgeries or serious injuries. All participants gave written informed consent for participation prior to testing. The study was carried out in accordance with the Declaration of Helsinki, and was previously approved by ethics committee of the International University of Health, Narita, Chiba, Japan (19-Io-62).

\section{2. $C A I$}

All participants were required to engage with the Cumberland Ankle Instability Tool (CAIT) [23], which consists of 9 items scored on a scale with a maximum of 30 points (Table 1). The survey included both ankles (dominant and nondominant sides). The CAIT and its Japanese version [24] have been proven to have high content validity and good reliability; the test can measure the severity of FAI as a numeric value. In accordance with Hiller et al. (2011) [23] and de Noronha et al. (2008) [25], we divided all participants into 
non-CAI ( $\geq 28$ points) and CAI ( $\leq 27$ points with a history of ankle sprain) groups for each of the dominant and nondominant legs.

Table 1. Nine items and scores of the Cumberland Ankle Instability Tool.

Q. Please Tick the One Statement in Each Question that Best Describes Your Ankles.

1. I have pain in my ankle

Never (5), During sport (4), Running on uneven surfaces (3), Running on level surfaces (2),

Walking on uneven surfaces (1), Walking on level surfaces (0)

2. My ankle feels UNSTABLE

Never (4), Sometimes during sport (not every time) (3), Frequently during sport (every time) (2), Sometimes during daily activity (1), Frequently during daily activity (0)

3. When I make SHARP turns, my ankle feels UNSTABLE

Never (3), Sometimes during running (2), Often when running (1), When walking (0)

4. When going down the stairs, my ankle feels UNSTABLE

Never (3), If I go fast (2), Occasionally (1), Always (0)

5. My ankle feels UNSTABLE when standing on ONE leg

Never (2), On the ball of my foot (1), With my foot fat (0)

6. My ankle feels UNSTABLE when

Never (3), I hop from side to side (2), I hop on the spot (1), When I jump (0)

7. My ankle feels UNSTABLE when

Never (4), I run on uneven surfaces (3), I jog on uneven surfaces (2), I walk on uneven surfaces (1), I walk on a fat surface (0)

8. TYPICALLY, when I start to roll over (or "twist") on my ankle, I can stop it Immediately (3), Often (2), Sometimes (1), Never (0), I have never rolled over on my ankle (3)

9. After a TYPICAL incident of my ankle rolling over, my ankle returns to "normal"

Almost immediately (3), Less than 1 day (2), 1-2 days (1), More than 2 days (0), I have never

rolled over on my ankle (3)

\subsection{Hip Joint Range of Motion (ROM)}

ROM in bilateral passive hip flexion, extension, abduction, internal rotation, and external rotation were measured using a standard goniometer, which has been shown to be a valid and reliable instrument for measuring hip ROM [26,27]. All hip ROM measurements were performed according to the methods and guidelines of the Japanese Association of Rehabilitation Medicine and the Japanese Orthopedic Association [28,29]. Hip flexion ROM was measured with the participant in the supine position, with the basic axis parallel to the trunk and the movement axis as the femur (the line connecting the greater trochanter and the center of the lateral femur). Hip extension ROM was measured with the subject in the prone position, with the basic axis parallel to the trunk and the movement axis as the femur (as above). Hip adduction and abduction ROMs were measured with the participant in the dorsal position, with the basic axis as the vertical line to the line connecting the iliac spines on both sides and the movement axis as the midfemoral line (the line connecting the center of the patella from the anterior superior iliac spine). Hip internal and external rotation ROMs were measured with the participant in the supine position, with the basic axis as the vertical line down from the patella and the movement axis as the center line of the lower leg (the line connecting the center of the patella to the center of the medial and lateral malleolus of the ankle). Prior to testing, no practice or warming-up was performed. All measurements were taken by a physical therapist blinded to the allocation, CAIT scores, and physical information of the participants. All participants were blinded to their own results after ROMs testing.

\subsection{Dynamic Balance by the Modified SEBT}

All participants completed the modified SEBT (mSEBT, Figure 1) [30]. The mSEBT is a reliable test for measuring single-limb stance excursion distances, and is used to measure 
dynamic balance ability in the lower extremity [30,31]. Three grid lines were drawn on the floor angled at 135 degrees apart from the center in the anterior, posteromedial, and posterolateral directions. The participants, standing on their dominant or nondominant leg in the center of the grid lines, performed maximum reach of each leg in each direction before returning to the start position. They reached for their nondominant leg when standing on their dominant leg, and their dominant leg when standing on their nondominant leg. All trials were also performed barefoot. All participants were instructed to keep their balance and to reach as far as possible in the anterior, posteromedial, and posterolateral directions. They were then required to touch the ground with their toes. The distance $(\mathrm{cm})$ from the center of the grid line to the maximum reaching position was measured by an examiner. The test was conducted for three successful trials in each direction, excluding failure trials in which the planter of the supporting leg was partly separated from the floor, balance was not maintained during reaching, or the trunk swayed significantly during the trial.

(A) Starting Position

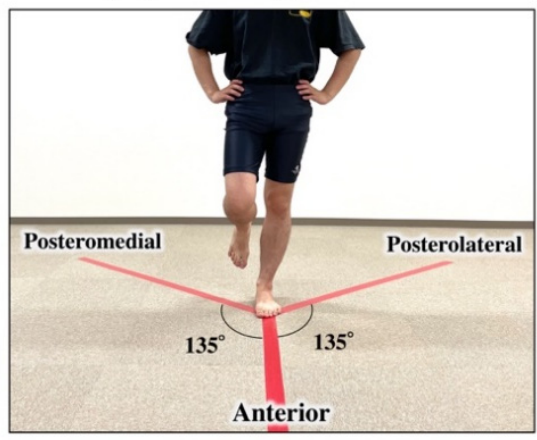

(C) Posteromedial

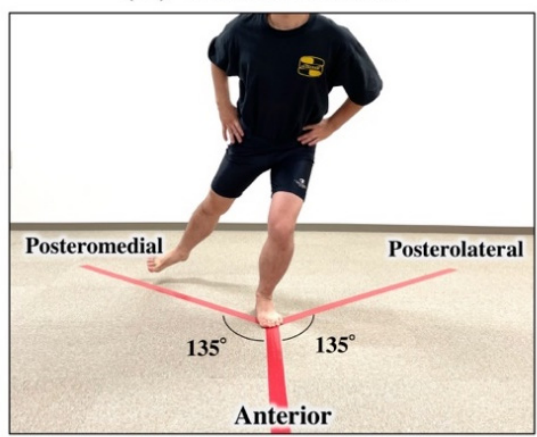

(B) Anterior

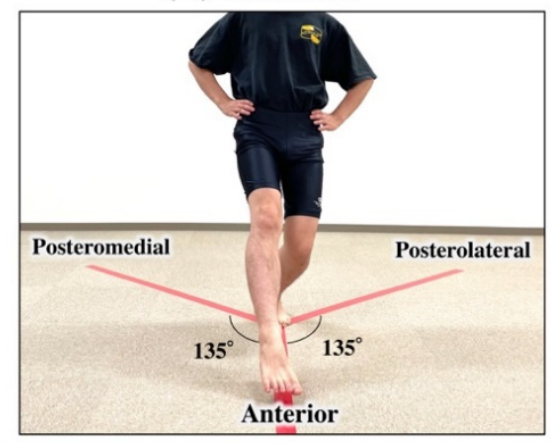

(D) Posterolateral

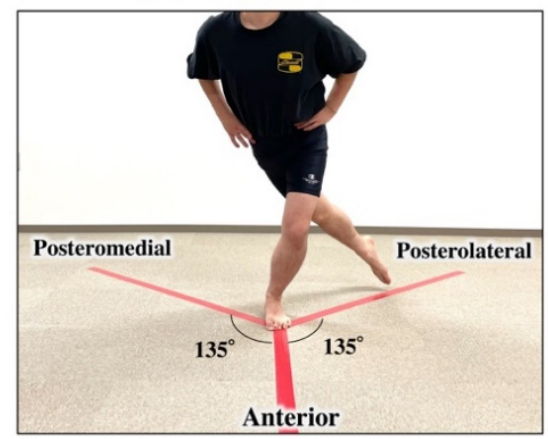

Figure 1. Modified Star Excursion Balance Test (mSEBT). Start position (A). Participants stand on their dominant or nondominant leg in the center of three grid lines, with their hands placed on the lower rib cage. All participants were instructed to keep their balance and to reach towards the other leg as far as possible in the anterior (B), posteromedial (C), and posterolateral directions (D). Finally, they touched the floor with their toes.

The distance for each direction of the mSEBT was normalized by the participant's leg length (LL) from the anterior superior iliac spine to the medial malleolus. The means (\%LL) and standard deviations of the mSEBT results were calculated from three successful trials in the anterior, posteromedial, and posterolateral directions. The mSEBT composite (\%LL) was calculated by summing the results of three reach directions and normalizing the results to leg length [30].

\subsection{Statistical Analysis}

Data analyses were conducted using IBM SPSS Statistics for Windows, version 24.0 (IBM Corporation, Armonk, NY, USA). The Kolmogorov-Smirnov test was used to confirm that hip ROMs and variables of the mSEBT were normally distributed $(p<0.05)$. According to whether a normal distribution existed, the Mann-Whitney U test or Student's $t$-test 
was selected to identify differences in variables in each leg between the CAI and non-CAI groups. According to whether a normal distribution existed, the Wilcoxon signed-rank or paired t-test was selected to identify differences between the dominant and nondominant legs. In order to mitigate the effects of the low numbers of participants in each group, Cohen's d effect sizes (ES) were calculated for all analyses to illustrate the magnitude of the differences between the groups. Pearson correlation coefficients were calculated for comparisons between hip internal/external rotation angles and mSEBT variables. A $p$-value of $<0.05$ was considered statistically significant.

\section{Results}

For the dominant leg, there were 7 players in the CAI group (mean CAIT score, $24.1 \pm 4.0$; mean age, $20.8 \pm 0.7$ years; mean height, $171.1 \pm 4.5 \mathrm{~cm}$; mean weight, $64.8 \pm 3.1 \mathrm{~kg}$; mean playing experience, $10.0 \pm 1.7$ years) and 10 players in non-CAI group (mean CAIT score, $28.9 \pm 2.1$; mean age, $20.8 \pm 1.0$ years; mean height, $175.1 \pm 5.2$ $\mathrm{cm}$; mean weight, $67.0 \pm 4.5 \mathrm{~kg}$; mean playing experience, $11.1 \pm 2.3$ years). For the nondominant leg, there were nine players in CAI group (mean CAIT score, $21.7 \pm 4.7$; mean age, $20.6 \pm 0.8$ years; mean height, $172.5 \pm 5.0 \mathrm{~cm}$; mean weight, $67.2 \pm 3.5 \mathrm{~kg}$; mean playing experience, $10.5 \pm 2.1$ years) and eight players in the non-CAI group (mean CAIT score, $28.7 \pm 1.4$; mean age, $20.9 \pm 0.9$ years; mean height, $172.8 \pm 5.5 \mathrm{~cm}$; mean weight, $64.9 \pm 4.1 \mathrm{~kg}$; mean playing experience, $10.5 \pm 2.1$ years). There were no significant differences in all physical characters between the CAI and non-CAI groups $(p>0.05)$.

There were no differences in the results for the anterior, posteromedial, and posterolateral directions, or for the composites of mSEBT while standing on the dominant and nondominant legs $(p>0.05$, Table 2$)$. There was no difference in hip ROMs between the dominant and nondominant legs $(p>0.05$, Table 2$)$, excluding the hip adduction angle (dominant leg, $18.5 \pm 13.1^{\circ}$; nondominant leg, $17.1 \pm 12.7^{\circ} ; p<0.00 ; \mathrm{ES}, 0.11$ ). The internal rotation angle had no significant correlation with the anterior $(\mathrm{R}=-0.15 ; p=0.53)$, posteromedial $(\mathrm{R}=-0.30 ; p=0.21)$, or posterolateral $(\mathrm{R}=-0.36 ; p=0.13)$ directions, or with the composite mSEBT $(\mathrm{R}=-0.35 ; p=0.13)$. The external rotation angle also had no correlation with the anterior $(\mathrm{R}=-0.05 ; p=0.83)$, posteromedial $(\mathrm{R}=-0.40 ; p=0.08)$, or posterolateral $(\mathrm{R}=-0.14 ; p=0.50)$ directions, or with the composite mSEBT $(\mathrm{R}=-0.22 ; p=0.36)$.

Table 2. Comparison of the mSEBT and ROM of hip and trunk between the dominant and nondominant legs.

\begin{tabular}{|c|c|c|c|c|}
\hline & Dominant Leg & Nondominant Leg & \multirow{2}{*}{$p$-Value } & \multirow{2}{*}{ Cohen's d ES } \\
\hline & Mean (SD) ${ }^{1}$ & Mean (SD) ${ }^{1}$ & & \\
\hline \multicolumn{5}{|l|}{ mSEBT $(\% L L)^{2}$} \\
\hline Anterior & $75.6(8.0)$ & $77.2(7.9)$ & 0.46 & 0.20 \\
\hline Posterolateral & $94.5(11.7)$ & $98.0(14.2)$ & 0.30 & 0.27 \\
\hline Posteromedial & $104.4(5.4)$ & $105.4(7.5)$ & 0.72 & 0.15 \\
\hline Composite & $91.5(8.4)$ & $93.5(9.9)$ & 0.49 & 0.22 \\
\hline \multicolumn{5}{|l|}{ Range of Motion (deg) } \\
\hline Hip Flexion & $123.6(6.1)$ & $125.3(5)$ & 0.25 & 0.30 \\
\hline Hip Extension & $18.9(2.9)$ & $18.1(2.9)$ & 0.23 & 0.26 \\
\hline $\begin{array}{l}\text { Hip External } \\
\text { Rotation }\end{array}$ & $41.6(7.9)$ & $45.6(6.9)$ & 0.12 & 0.54 \\
\hline $\begin{array}{l}\text { Hip Internal } \\
\text { Rotation }\end{array}$ & $35.9(9.4)$ & 36.7 (10.9) & 0.66 & 0.08 \\
\hline Hip Abduction & $36.5(4.5)$ & $36.9(4.1)$ & 0.67 & 0.08 \\
\hline Hip Adduction & $17.1(12.7)$ & $18.5(13.1)$ & $0.00 *$ & 0.11 \\
\hline Trunk Flexion & \multicolumn{2}{|c|}{$39.2(4.8)$} & - & - \\
\hline Trunk Lt Rotation & \multicolumn{2}{|c|}{$46.4(5.1)$} & - & - \\
\hline Trunk Rt Rotation & \multicolumn{2}{|c|}{$42.2(4.8)$} & - & - \\
\hline
\end{tabular}

${ }^{1}$ Data are reported as mean (standard deviation). ${ }^{2}$ The maximum reach distance toward the other leg while standing on the dominant and nondominant legs. ${ }^{*} p$-values of $<0.01$ were considered statistically significant between the dominant and the nondominant groups. 
While standing on the nondominant leg, there were no differences in the anterior, posteromedial, or posterolateral directions, or in the composite of mSEBT between the CAI and non-CAI groups ( $p>0.05$, Table 3$)$. There were also no differences in hip and trunk ROMs between the CAI and non-CAI groups $(p>0.05$, Table 4$)$. While standing on the dominant leg, reach in the posterolateral direction in the CAI group was significantly less than in the non-CAI group ( $p=0.046$; ES, 1.05; Table 2$)$, while there were no significant differences between the CAI and non-CAI groups for the anterior and posteromedial directions or the composites of mSEBT. The hip extension ( $p=0.04 ; \mathrm{ES}, 1.11)$ and internal rotation ( $p=0.047 ; \mathrm{ES}, 1.03)$ angles in the dominant leg in the CAI group were greater than those in the non-CAI group (Table 4).

Table 3. mSEBT of the dominant and the nondominant legs in the CAI and non-CAI groups.

\begin{tabular}{|c|c|c|c|c|c|c|c|c|}
\hline & \multicolumn{2}{|c|}{ Dominant Leg ${ }^{1}$} & \multirow{2}{*}{$p$-Value } & \multirow{2}{*}{$\begin{array}{c}\text { Cohen's d } \\
\text { ES }\end{array}$} & \multicolumn{2}{|c|}{ Nondominant Leg ${ }^{1}$} & \multirow{2}{*}{$p$-Value } & \multirow{2}{*}{$\begin{array}{c}\text { Cohen's d } \\
\text { ES }\end{array}$} \\
\hline & $\begin{array}{c}\text { CAI } \\
(n=7)\end{array}$ & $\begin{array}{c}\text { Non-CAI } \\
(n=10)\end{array}$ & & & $\begin{array}{c}\text { CAI } \\
(n=9)\end{array}$ & $\begin{array}{c}\text { Non-CAI } \\
(\mathrm{n}=8)\end{array}$ & & \\
\hline Anterior (\%LL) & $75.6(8)$ & $77.2(7.9)$ & 0.46 & 0.20 & $77.9(7.6)$ & $76.5(8.8)$ & 0.74 & 0.17 \\
\hline Posterolateral (\%LL) & $94.5(11.7)$ & $98.0(14.2)$ & 0.30 & 0.27 & $91.7(13.7)$ & $105.1(11.7)$ & $0.046^{*}$ & 1.05 \\
\hline Posteromedial (\%LL) & $104.4(5.4)$ & $105.4(7.5)$ & 0.72 & 0.15 & $105.9(6)$ & $104.9(9.3)$ & 0.80 & 0.12 \\
\hline Composite Score (\%) & $91.5(8.4)$ & $93.5(9.9)$ & 0.49 & 0.22 & $91.8(9.1)$ & $95.5(9.9)$ & 0.53 & 0.10 \\
\hline
\end{tabular}

${ }^{1}$ Data are reported as mean (standard deviation). ${ }^{*} p$-values of $<0.05$ were considered statistically significant between the CAI and non-CAI groups.

Table 4. Hip and trunk measurements of the dominant and the nondominant legs in the CAI and non-CAI groups.

\begin{tabular}{|c|c|c|c|c|c|c|c|c|}
\hline & \multicolumn{2}{|c|}{ Dominant Leg $^{1}$} & \multirow{2}{*}{$p$-Value } & \multirow{2}{*}{$\begin{array}{c}\text { Cohen's d } \\
\text { ES }\end{array}$} & \multicolumn{2}{|c|}{ Nondominant Leg ${ }^{1}$} & \multirow{2}{*}{$p$-Value } & \multirow{2}{*}{$\begin{array}{c}\text { Cohen's d } \\
\text { ES }\end{array}$} \\
\hline & $\begin{array}{c}\text { CAI } \\
(n=7)\end{array}$ & $\begin{array}{l}\text { Non-CAI } \\
(\mathrm{n}=10)\end{array}$ & & & $\begin{array}{c}\text { CAI } \\
(n=9)\end{array}$ & $\begin{array}{c}\text { Non-CAI } \\
(n=8)\end{array}$ & & \\
\hline Hip Flexion & $122.6(8.2)$ & $123.6(4.4)$ & 0.56 & 0.16 & $123.8(5.9)$ & $127.0(3.2)$ & 0.19 & 0.68 \\
\hline Hip Extension & $17.7(1.7)$ & $19.5(3.4)$ & 0.17 & 0.69 & $19.4(3.0)$ & $16.6(2.0)$ & $0.04 *$ & 1.11 \\
\hline Hip External Rotation & $42.1(6.0)$ & $41.7(9.3)$ & 0.84 & 0.05 & $45.8(4.5)$ & $45.5(9.2)$ & 0.94 & 0.04 \\
\hline Hip Internal Rotation & $34.1(10.1)$ & $37.1(9.2)$ & 0.54 & 0.31 & $41.6(6.4)$ & $31.3(12.6)$ & $0.047^{*}$ & 1.03 \\
\hline Hip Abduction & $35.3(4.3)$ & $37.4(4.6)$ & 0.35 & 0.47 & $35.6(4.1)$ & $38.4(3.7)$ & 0.16 & 0.72 \\
\hline Hip Adduction & $17.4(16.6)$ & $16.5(10.1)$ & 0.92 & 0.06 & $14.4(1.1)$ & $23.1(18.6)$ & 0.18 & 0.66 \\
\hline Trunk Flexion & $38.4(2.6)$ & $39.5(5.9)$ & 0.58 & 0.24 & $39.6(4.3)$ & $38.9(5.5)$ & 0.78 & 0.14 \\
\hline Trunk Lt Rotation & $48.6(3.6)$ & $44.5(5.5)$ & 0.14 & 0.88 & $47.3(4.0)$ & $45.3(6.2)$ & 0.42 & 0.40 \\
\hline Trunk Rt Rotation & $42.3(3.7)$ & $42.0(5.6)$ & 0.97 & 0.06 & $42.4(3.2)$ & $42.0(6.3)$ & 0.85 & 0.09 \\
\hline
\end{tabular}

${ }^{1}$ Data are reported as mean (standard deviation). ${ }^{*} p$-values of $<0.05$ were considered statistically significant between the CAI and non-CAI groups.

\section{Discussion}

The results of the mSEBT test show that the dominant leg in soccer players with CAI has poor dynamic balance ability while reaching towards the nondominant leg in the posterolateral direction. In the mSEBT, the participants must keep their balance by performing trunk side-flexion and rotation toward their supporting leg, as well as hip flexion, adduction, and internal rotation [32]. In particular, reaching in the posterolateral direction requires greater angles of hip flexion, adduction, and trunk side-flexion (toward their supporting leg) than reaching in the anterior or posteromedial directions [32]. Our ROM results for the trunk and hip show no relationship with dynamic balance ability, as evaluated by the mSEBT. This implies that hip flexibility may be important for dynamic balance control. Thus, it may not always be necessary for soccer players to acquire hip flexibility in order to improve their dynamic balance ability.

Previous studies have reported that CAI cases demonstrate a decreased knee flexion during landing tasks [33], stiffness in the hip during single leg landings [34], and greater hip/knee flexion during the stance phase in cross cutting [35]. These reports indicate 
that participants with CAI may have reduced dynamic balance ability while reaching in the posterolateral direction, without using proximal joints to compensate for distal joint instability. Furthermore, this study revealed that soccer players with CAI had a large hip internal rotation ROM. This result suggests that the flexibility of the hip joint may enable control of the pelvic and dynamic posture. Yet, in soccer players with CAI, the dynamic balance ability in the posterolateral direction could not be maintained, which is thought to be because the required contribution of muscle strength is greater than that of hip flexibility. As the participants reach backward across the supporting leg, their trunk tilts anteriorly to maintain their center of mass on the supporting leg. In addition, a previous study has reported on the influence of hip strength on dynamic postural control performance in participants with CAI [36,37]. Jaber et al. (2018) suggested that alterations in the gluteus maximus muscle activity in participants with CAI appear to negatively affect postural control in the posterolateral direction and quality of movement, which could lead to prolonged functional impairment [37]. Such reports indicate that participants with CAI may be unable to use the gluteus maximus muscle to maintain the stability of the hip joint while reaching in the posterolateral direction. For reaching in the posterolateral direction, the horizontal axis of the pelvis should be maintained on the supporting leg.

The most recent biomechanical research into maintaining kicking performance in soccer players has focused on the dynamic stability of the supporting leg [38,39]. Inoue et al. (2014) clarified that the supporting leg plays the role of attenuating impact during initial contact in the kicking motion [38]. They also reported that the dynamic stability of the supporting leg contributes to the swing velocity of the kicking leg [38]. ChewBullock et al. (2014) clarified that the single leg balance ability in the supporting leg affects kicking accuracy in the kicking leg [40]. These reports suggest that dynamic balance in the supporting leg in soccer players is an important physical and functional factor for maintaining or improving the kicking performance. Our results show no significant relationship between hip flexibility and the dynamic balance ability in the dominant or nondominant legs. Differences in the dynamic balance ability between the CAI and nonCAI groups were present only in the kicking leg (dominant leg); there were no characteristic results in the supporting leg (nondominant leg). It is considered necessary to investigate the physical condition of the trunk and hips in soccer player with CAI, for the prevention of secondary injuries and the improvement of dynamic balance performance.

This study has a limitation. Mechanical ankle instability was not evaluated because the CAIT score was used to measure severity when evaluating CAI. Mechanical instability is defined as ankle movement beyond the physiological limit of the ankle's ROM [41]. CIA occurs due to mechanical instability, functional instability, or, most likely, a combination of CAI and MAI phenomena [12]. Therefore, it may be necessary to evaluate both mechanical and functional ankle instabilities when evaluating CAI after an ankle sprain.

\section{Conclusions}

The dominant leg in soccer players with CAI had a poor dynamic balance ability while reaching in the posterolateral direction, and a large hip internal rotation ROM. However, the results of trunk and hip ROMs showed no relationship to dynamic balance ability. It may not always be necessary to acquire hip flexibility in order to improve the dynamic balance ability. Soccer players with CAI have reduced dynamic balance ability while reaching in the posterolateral direction, as they do not use the proximal joints to compensate for distal joint instability. We expect our results to contribute to the development of future research, as basic material for future investigations that examine performance improvement and the prevention of disability in soccer players with CAI. 
Author Contributions: Conceptualization, A.T.; methodology, A.T. and K.S.; software, A.T. and K.S.; validation, A.T., K.S. and Y.I.; formal analysis, A.T.; investigation, A.T. and K.S.; resources, A.T. and K.S.; data curation, A.T. and K.S.; writing-original draft preparation, A.T.; writing-review and editing, K.S.; visualization, A.T. and K.S.; supervision, Y.I.; project administration, A.T. and Y.I.; funding acquisition, none. All authors have read and agreed to the published version of the manuscript.

Funding: This research received no external funding.

Institutional Review Board Statement: The study was conducted according to the guidelines of the Declaration of Helsinki, and was approved by the ethics committee of the International University of Health, Narita, Chiba, Japan (19-Io-62).

Informed Consent Statement: Informed consent was obtained from all participants involved in the study.

Data Availability Statement: The data presented in this study are available on request from the corresponding author. The data are not publicly available due to privacy concerns.

Conflicts of Interest: The authors declare no conflict of interest.

\section{References}

1. Swenson, D.M.; Collins, C.L.; Fields, S.K.; Comstock, R.D. Epidemiology of US High School Sports-Related Ligamentous Ankle Injuries, 2005/06-2010/11. Clin. J. Sport Med. 2013, 23, 190-196. [CrossRef]

2. Waldén, M.; Hägglund, M.; Ekstrand, J. Time-trends and circumstances surrounding ankle injuries in men's professional football: An 11-year follow-up of the UEFA Champions League injury study. Br. J. Sports Med. 2013, 47, 748-753. [CrossRef]

3. Woods, C.; Hawkins, R.; Hulse, M.; Hodson, A. The Football Association Medical Research Programme: An audit of injuries in professional football: An analysis of ankle sprains. Br. J. Sports Med. 2003, 37, 233-238. [CrossRef] [PubMed]

4. Walls, R.J.; Ross, K.; Fraser, E.J.; Hodgkins, C.W.; Smyth, N.A.; Egan, C.J.; Calder, J.; Kennedy, J.G. Football injuries of the ankle: A review of injury mechanisms, diagnosis and management. World J. Orthop. 2016, 7, 8-19. [CrossRef]

5. Yeung, M.S.; Chan, K.M.; So, C.H.; Yuan, W.Y. An epidemiological survey on ankle sprain. Br. J. Sports Med. 1994, $28,112-116$. [CrossRef]

6. Tyler, T.F.; McHugh, M.P.; Mirabella, M.R.; Mullaney, M.J.; Nicholas, S.J. Risk Factors for Noncontact Ankle Sprains in High School Football Players. Am. J. Sports Med. 2006, 34, 471-475. [CrossRef]

7. Jain, N.; Murray, D.; Kemp, S.; Calder, J. Frequency and trends in foot and ankle injuries within an English Premier League Football Club using a new impact factor of injury to identify a focus for injury prevention. Foot Ankle Surg. 2014, 20, 237-240. [CrossRef] [PubMed]

8. Hiller, C.E.; Kilbreath, S.; Refshauge, K. Chronic Ankle Instability: Evolution of the Model. J. Athl. Train. 2011, 46, 133-141. [CrossRef]

9. Hiller, C.E.; Nightingale, E.J.; Lin, C.-W.C.; Coughlan, G.F.; Caulfield, B.; Delahunt, E. Characteristics of people with recurrent ankle sprains: A systematic review with meta-analysis. Br. J. Sports Med. 2011, 45, 660-672. [CrossRef]

10. Tanen, L.; Docherty, C.L.; Van Der Pol, B.; Simon, J.; Schrader, J. Prevalence of Chronic Ankle Instability in High School and Division I Athletes. Foot Ankle Spéc. 2013, 7, 37-44. [CrossRef] [PubMed]

11. Freeman, M.A. Instability of the foot after injuries to the lateral ligament of the ankle. J. Bone Jt. Surg. Br. 1965, 47, 669-677. [CrossRef]

12. Hertel, J. Functional anatomy, pathomechanics, and pathophysiology of lateral ankle instability. J. Athl. Train. 2002, 37, 364-375.

13. McKeon, P.O.; Hertel, J. Systematic review of postural control and lateral ankle instability, part I: Can deficits be detected with instrumented testing. J Athl. Train. 2008, 43, 293-304. [CrossRef]

14. Boyle, J.; Negus, V. Joint position sense in the recurrently sprained ankle. Aust. J. Physiother. 1998, 44, 159-163. [CrossRef]

15. Hintermann, B.; Boss, A.; Schäfer, D. Arthroscopic findings in patients with chronic ankle instability. Am. J. Sports Med. 2002, 30, 402-409. [CrossRef]

16. Khalaj, N.; Vicenzino, B.; Smith, M.D. Hip and knee muscle torque and its relationship with dynamic balance in chronic ankle instability, copers and controls. J. Sci. Med. Sport. 2021, 24, 647-652. [CrossRef]

17. McCann, R.S.; Terada, M.; Kosik, K.B.; Gribble, P.A. Landing kinematics and isometric hip strength of individuals with chronic ankle instability. Foot Ankle Int. 2019, 40, 969-977. [CrossRef] [PubMed]

18. Freke, M.; Kemp, J.; Semciw, A.; Sims, K.; Russell, T.; Singh, P.; Crossley, K. Hip Strength and Range of Movement Are Associated with Dynamic Postural Control Performance in Individuals Scheduled for Arthroscopic Hip Surgery. J. Orthop. Sports Phys. Ther. 2018, 48, 280-288. [CrossRef]

19. Robinson, R.; Gribble, P. Kinematic predictors of performance on the Star Excursion Balance Test. J. Sport Rehabil. 2008, 17, 347-357. [CrossRef] [PubMed] 
20. Endo, Y.; Sakamoto, M. Relationship between Lower Extremity Tightness and Star Excursion Balance Test Performance in Junior High School Baseball Players. J. Phys. Ther. Sci. 2014, 26, 661-663. [CrossRef]

21. Gribble, P.A.; Kelly, S.E.; Refshauge, K.; Hiller, C.E. Interrater Reliability of the Star Excursion Balance Test. J. Athl. Train. 2013, 48, 621-626. [CrossRef] [PubMed]

22. Kinzey, S.J.; Armstrong, C.W. The Reliability of the Star-Excursion Test in Assessing Dynamic Balance. J. Orthop. Sports Phys. Ther. 1998, 27, 356-360. [CrossRef] [PubMed]

23. Hiller, C.E.; Refshauge, K.M.; Bundy, A.C.; Herbert, R.D.; Kilbreath, S.L. The Cumberland Ankle Instability Tool: A Report of Validity and Reliability Testing. Arch. Phys. Med. Rehabil. 2006, 87, 1235-1241. [CrossRef] [PubMed]

24. Kunugi, S.; Masunari, A.; Noh, B.; Mori, T.; Yoshida, N.; Miyakawa, S. Cross-cultural adaptation, reliability, and validity of the Japanese version of the Cumberland ankle instability tool. Disabil. Rehabil. 2016, 39, 50-58. [CrossRef] [PubMed]

25. De Noronha, M.; Refshauge, K.M.; Crosbie, J.; Kilbreath, S.L. Relationship Between Functional Ankle Instability and Postural Control. J. Orthop. Sports Phys. Ther. 2008, 38, 782-789. [CrossRef] [PubMed]

26. Roach, S.; Juan, J.S.; Suprak, D.N.; Lyda, M. Concurrent Validity of Digital Inclinometer and Universal Goniometer in Assessing Passive Hip Mobility in Healthy Subjects. Int. J. Sports Phys. Ther. 2013, 8, 680-688.

27. Nussbaumer, S.; Leunig, M.; Glatthorn, J.F.; Stauffacher, S.; Gerber, H.; Maffiuletti, N.A. Validity and test-retest reliability of manual goniometers for measuring passive hip range of motion in femoroacetabular impingement patients. BMC Musculoskelet. Disord. 2010, 11, 194. [CrossRef]

28. Yonemoto, K.; Ishigami, S.; Kondo, T. The method guidelines for range of motion measurement. Jpn. J. Rehabil. Med. 1995, 32, 207-217.

29. Han, H.; Kubo, A.; Kurosawa, K.; Maruichi, S.; Ishizaka, M.; Sadakiyo, K.; Nomura, T.; Honzawa, K. Ipsilateral patterns of the rotational range of motion of the hip in healthy Japanese adults. J. Phys. Ther. Sci. 2016, 28, 2550-2555. [CrossRef] [PubMed]

30. van Lieshout, R.; Reijneveld, E.A.; van den Berg, S.M.; Haerkens, G.M.; Koenders, N.H.; de Leeuw, A.J.; van Oorsouw, R.G.; Paap, D.; Scheffer, E.; Weterings, S.; et al. Reproducibility of the modified star excursion balance test composite and specific reach direction scores. Int. J. Sports Phys. Ther. 2016, 11, 356-365.

31. Denehey, T.; Marshall, T.; Spaccarotella, K.; Andzel, W. The Impact of an External Load of Football Equipment on Dynamic Balance as Assessed by the Modified Star Excursion Balance Test. Int. J. Exerc. Sci. 2018, 11, 797-805.

32. Uebayashi, K.; Akasaka, K.; Tamura, A.; Otsudo, T.; Sawada, Y.; Okubo, Y.; Hall, T. Characteristics of trunk and lower limb alignment at maximum reach during the Star Excursion Balance Test in subjects with increased knee valgus during jump landing. PLoS ONE 2019, 14, e0211242. [CrossRef]

33. Doherty, C.; Bleakley, C.; Hertel, J.; Caulfield, B.; Ryan, J.; Delahunt, E. Single-leg drop landing movement strategies in participants with chronic ankle instability compared with lateral ankle sprain 'copers'. Knee Surg. Sports Traumatol. Arthrosc. 2015, 24, 1049-1059. [CrossRef] [PubMed]

34. Koshino, Y.; Yamanaka, M.; Ezawa, Y.; Ishida, T.; Kobayashi, T.; Samukawa, M.; Saito, H.; Takeda, N. Lower limb joint motion during a cross cutting movement differs in individuals with and without chronic ankle instability. Phys. Ther. Sport 2014, 15, 242-248. [CrossRef]

35. Inoue, K.; Nunome, H.; Sterzing, T.; Shinkai, H.; Ikegami, Y. Dynamics of the support leg in soccer instep kicking. J. Sports Sci. 2014, 32, 1023-1032. [CrossRef] [PubMed]

36. McCann, R.S.; Crossett, I.D.; Terada, M.; Kosik, K.B.; Bolding, B.A.; Gribble, P.A. Hip strength and star excursion balance test deficits of patients with chronic ankle instability. J. Sci. Med. Sport 2017, 20, 992-996. [CrossRef] [PubMed]

37. Jaber, H.; Lohman, E.; Daher, N.; Bains, G.; Nagaraj, A.; Mayekar, P.; Shanbhag, M.; Alameri, M. Neuromuscular control of ankle and hip during performance of the star excursion balance test in subjects with and without chronic ankle instability. PLoS ONE 2018, 13, e0201479. [CrossRef]

38. Theisen, A.; Day, J. Chronic Ankle Instability Leads to Lower Extremity Kinematic Changes During Landing Tasks: A Systematic Review. Int. J. Exerc. Sci. 2019, 12, 24-33.

39. Augustus, S.; Mundy, P.; Smith, N. Support leg action can contribute to maximal instep soccer kick performance: An intervention study. J. Sports Sci. 2016, 35, 89-98. [CrossRef] [PubMed]

40. Chew-Bullock, T.S.-Y.; Anderson, D.I.; Hamel, K.A.; Gorelick, M.L.; Wallace, S.A.; Sidaway, B. Kicking performance in relation to balance ability over the support leg. Hum. Mov. Sci. 2012, 31, 1615-1623. [CrossRef]

41. Tropp, H. Commentary: Functional Ankle Instability Revisited. J. Athl. Train. 2002, 37, 512-515. [PubMed] 